\section{Neuroendocrine tumor of the extrahepatic bile duct: a tumor in an unusual site visualized by cholangioscopy}

A 78-year-old man who had previously undergone a cholecystectomy was admitted with symptoms of obstructive jaundice and cholangitis. The endoscopic ultrasound (EUS) showed a hypoechoic mass in the distal common bile duct (CBD) with no signs of vascular invasion or metastatic nodes ( $\bullet$ Fig. 1). The patient underwent endoscopic retrograde cholangiopancreatography (ERCP), which revealed a filling defect of approximately $1.5 \mathrm{~cm}($ Fig. 2) with severe obstruction at the mid CBD and upstream biliary dilatation. Cholangioscopy with SpyGlass (Boston Scientific, Natick, Massachusetts, USA) showed a superficially ulcerated exophytic mass arising from the bile duct mucosa with a CBD stricture ( Fig. 3; - Video 1). Endoluminal biopsies performed with SpyBite (Boston Scientific) showed inflammatory changes of the epithelium with necrotic material. A stent was inserted through the stricture. He underwent pancreaticoduodenectomy.

The gross appearance of the resected specimen showed a poorly demarcated intramural and exophytic mass measuring $3 \mathrm{~cm}$ that was causing thickening of the duct wall.

Histological examination revealed a proliferation of monotonous cells with round or oval nuclei with scanty pink cytoplasm.

\section{Video 1}

Cholangioscopy with SpyGlass showing an intraluminal ulcerated mass arising from the bile duct mucosa with a common bile duct (CBD) stricture that was not passable with the 10-Fr SpyScope.
The cells were arranged in sheets with no organoid pattern. There were 20 mitotic figures per 10 high-power fields. There was evidence of necrosis and vascular invasion. The resection margins and lymph nodes were free of tumor. Immunohistochemical analysis showed that the neoplastic cells were positive for chromogra$\operatorname{nin}$ A, synaptophysin, CD 56, with nuclear expression of P53 ( $\bullet$ Fig. 4). The proliferation index (Mib-1) was $<20 \%$.

Endocrine tumors originate from cells of the dispersed endocrine system, which are distributed in many organs and tissues including the bile ducts [1]. Because of their rarity, pre-operative diagnosis of endocrine tumors is difficult. The presenting symptoms are usually secondary to the mass effect of the tumor and, because jaundice is the most common symptom, ERCP with cholangioscopy is considered the best approach for diagnosis and palliative treatment. However, such tumors are frequently misdiagnosed as a cholangiocarcinoma.

Endoscopy_UCTN_Code_CCL_1AZ_2AC

Competing interests: None

\section{De Luca', S. Tommasoni², \\ A. de Leone ${ }^{1}$, M. L. Bianchi ${ }^{1}$, \\ M. de Nictolis ${ }^{2}$, D. Baroncini ${ }^{1}$}

${ }^{1}$ Gastroenterology and Digestive Endoscopy Unit, San Salvatore Hospital, Pesaro, Italy

2 Department of Anatomical Pathology, San Salvatore Hospital, Pesaro, Italy

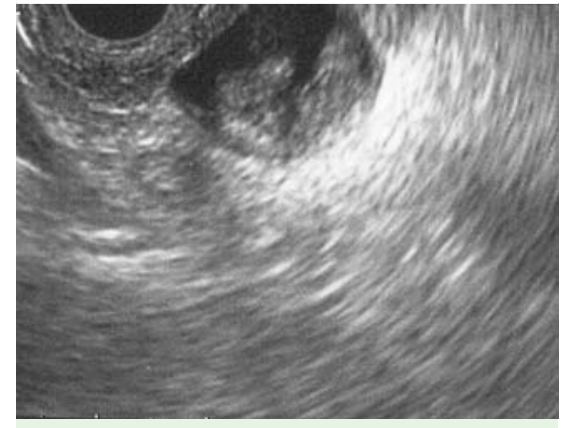

Fig. 1 Endoscopic ultrasound (EUS) appearance in a 78-year-old man with obstructive jaundice who had previously undergone a cholecystectomy showing a hypoechoic mass in the lumen of the distal common bile duct (CBD) without signs of vascular invasion or metastatic nodes.

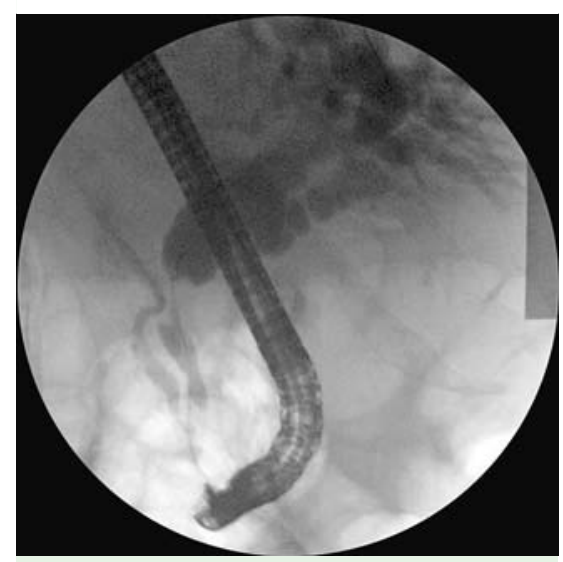

Fig. 2 Endoscopic retrograde cholangiopancreatography (ERCP) image revealing a filling defect that measured approximately $1.5 \mathrm{~cm}$ with severe obstruction at the mid common bile duct (CBD) and upstream biliary dilatation.

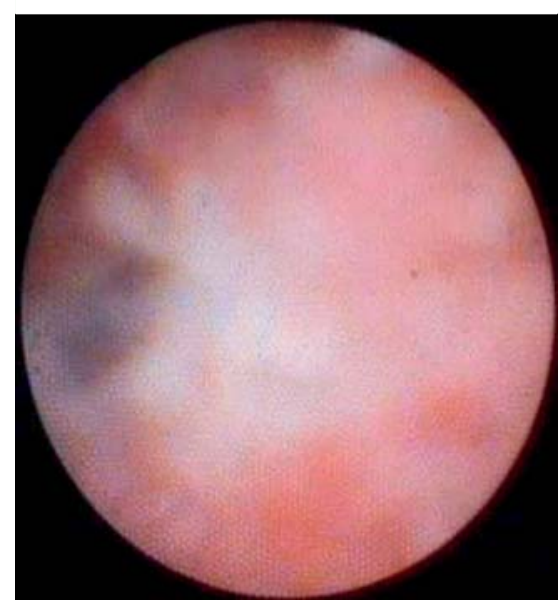

Fig. 3 View during cholangioscopy with SpyGlass showing a superficially ulcerated intraluminal mass arising from the bile duct mucosa and a common bile duct (CBD) stricture. 


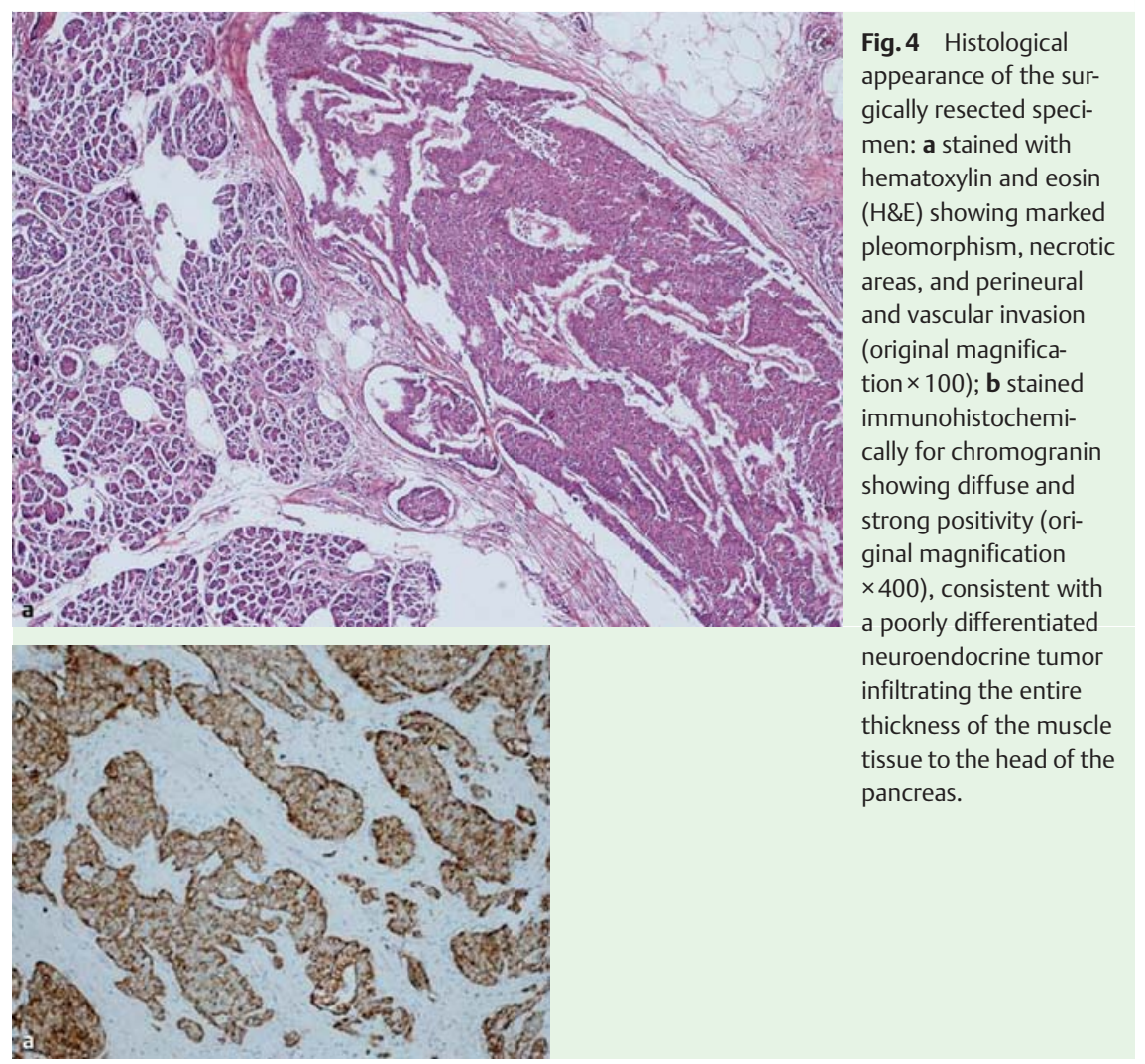

\section{References}

1 Rassi ZS, Mohsine RM, Berger F et al. Endocrine tumors of the extrahepatic bile ducts. Pathological and clinical aspects, surgical management and outcome. Hepatogastroenterology 2004; 51: $1295-1300$

\section{Bibliography}

Dol http://dx.doi.org/

10.1055/s-0032-1326453

Endoscopy 2013; 45: E338-E339

(c) Georg Thieme Verlag KG

Stuttgart · New York

ISSN 0013-726X

\section{Corresponding author}

\section{De Luca, MD}

Gastroenterology and Digestive Endoscopy Unit Ospedale San Salvatore

Piazzale Cinelli

1-61100 Pesaro

Italy

Fax: +39-721-362285

lucadeluca1210@gmail.com 